\title{
THE EVOLUTION OF THE SEMANTIC PERCEPTION OF THE PHENOMENA AND PROCESSES IN THE MEDICAL AND SOCIAL SPHERE
}

\author{
Artem A. Boboshko \\ Volgograd State University, Volgograd, Russian Federation; \\ Public Chamber of the City of Sevastopol, Sevastopol, Russian Federation
}

\begin{abstract}
This article is devoted to the analysis of the evaluation of the semantic perception of the processes in society, which deal with health, medical services, the quality of life in the period of social transformation at the end of 20th century and the beginning of the 21 st. The author finds out the main reasons of changing of society attitude to social and personal health. Based on the analysis of social-philosophic approaches towards understanding the value of health and person's attitude to his own life and are revealed dynamic of meanings in medical and social sphere, the sources of the formation of modern concepts of the social significance of health. Having justifyed the versatility of the modern understanding of health, which isn't limited to the studying of the physical condition of the body, but it is also included mental, physic and social well-being, the author relies on the world organization of Health Care (WON), so the health means as a resource of everyday life, not so the health as am. Beyond the boundaries of the definition, those needs remain that are characteristic of a healthy person. In this regard the discussions haven't been stopping around the concept of health and currently, continuing that many concepts, based on different understanding of the essence of health. Health is priceless as a subjective factor, but it has an economic component from the point of view of social protection. According to the author's opinion, these factors prove the need for a new social model of medical services for the population. In the historic context the perception of meanings, related to the health and medical service, was formed by each specific epoch of development, manifesting itself in the ideas of the philosophers. Modern sociological science allows us to identity public opinion about medical-social sphere and based on its analysis, to correct the policy in this area, relying on the knowledge of social needs.
\end{abstract}

Key words: social value, social construction, quality of life, health, medical care, social practice.

Citation. Boboshko A.A. The Evolution of the Semantic Perception of the Phenomena and Processes in the Medical and Social Sphere. Logos et Praxis, 2021, vol. 20, no. 3, pp. 146-155. (in Russian). DOI: https://doi.org/ 10.15688/lp.jvolsu.2021.3.14

УДК 316.42

ББК 60.56

\section{ЭВОЛЮЦИЯ СМЫСЛОВОГО ВОСПРИЯТИЯ ЯВЛЕНИЙ И ПРОЦЕССОВ В МЕДИКО-СОЦИАЛЬНОЙ СФЕРЕ}

\author{
Артем Андреевич Бобошко \\ Волгоградский государственный университет, г. Волгоград, Российская Федерация; \\ Общественная палата г. Севастополя, г. Севастополь, Российская Федерация
}


чимости здоровья. Обосновывая многогранность современного понимания здоровья, которое не ограничивается изучением физического состояния тела, а включает в себя психическое, душевное и социальное благополучие, автор опирается на определение Всемирной организации здравоохранения (ВОЗ), основывающееся на понимании здоровья как ресурса каждодневной жизни, а не цели жизни. Однако при этом за границами определения остаются те потребности, которые свойственны здоровому человеку. В связи с этим дискуссии вокруг понятия здоровья не прекращаются и в настоящее время, порождая множество концепций, основанных на различном понимании его сущности. Здоровье бесценно как субъективный фактор, но имеет и вполне вычисляемую экономическую составляющую с точки зрения социальной защиты. Эти факты, по мнению автора, доказывают необходимость появления новой социально адаптированной модели медицинского обслуживания населения. В историческом контексте восприятие смыслов, относящихся к здоровью и медицинскому обслуживанию, формировалось каждой конкретной эпохой развития, проявляясь в идеях мыслителей. Современная социологическая наука позволяет выявить общественное мнение о медико-социальной сфере и на основе его анализа корректировать политику в этой области, опираясь на знание общественных потребностей.

Ключевые слова: социальная ценность, социальный механизм, качество жизни, здоровье, медицинское обслуживание, социальная практика.

Цитирование. Бобошко А. А. Эволюция смыслового восприятия явлений и процессов в медико-социальной сфере // Logos et Praxis. - 2021. - T. 20, № 3. - C. 146-155. -DOI: https://doi.org/10.15688/lp.jvolsu.2021.3.14

Трансформация медицинского обслуживания в постиндустриальном (информационном) обществе в России и мире в целом вызвана изменениями в системе социальных отношений, инверсией в отношении к здоровью и к медицине, диверсификацией коммуникаций с работниками медицинской сферы и т. д. Стало очевидно, что модели медицинского обслуживания предыдущих общественных формаций устарели. Доказательством этого являются многочисленные попытки адаптации медицинского обслуживания к требованиям времени. Увы, технические приемы в виде модернизации, изменения каналов финансирования, оптимизации различных рангов, цифровизации не дают каких-либо существенных результатов в улучшении здравоохранения. Пандемия 2020 г., охватившая значительное количество стран мира, вызванная возбудителем SARS-CoV-2, которая в большей степени имеет социальные последствия, нежели медицинские, является прямым доказательством необходимости появления новой модели медицинского обслуживания населения, построенной на медико-социальных критериях, а не экономической целесообразности.

Даже находясь в смысловых рамках определенной общественной системы, социолог не всегда достигает более или менее очевидного понимания связей и взаимодействий различных аспектов теоретического и эмпирического восприятия изучаемого объекта. Однако эти затруднения многократно возрастают во время глобальных исторических изменений. Зрелище получается масштабным, завораживающим своим величием, недаром, древнекитайская мудрость предупреждает нас: «Не дай вам бог жить в эпоху перемен!»

На рубеже XX-XXI вв. Россия пережила период социально-политических, экономических и культурных трансформаций, изменивших общественную ситуацию в стране, систему ценностей, парадигмы осмысления смысла жизни и существования человека. Само понятие «жизнь» приобрело новое социальное измерение, а вместе с этим иными смыслами наполнились понятия «качество жизни», «здоровье», «охрана здоровья». На первый взгляд может показаться, что нет суждений более близких и понятных человеку, чем перечисленные, но иллюзия сразу исчезает, как только от привычной рассудочности мы отваживаемся выйти на простор теоретического исследования, временной масштаб которого - историческое время в целом, тогда как рассудок оперирует в рамках определенного временного интервала. Сознание пытается «частное» представить как «общее» и ставит перед исследователем серьезную социологическую задачу: найти такую систему социальных индикаторов, которая бы надежно репрезентировала социальные связи и взаимодействия в базовых социальных институтах, вырабатывающих главный продукт истории - человека. И тогда становится ясно, что вопросы человеческого здоровья превращаются в важное поле исследования. 
Масштаб проблемы не исключает, а предполагает выделение отдельных этапов решения, выстраивания динамики различных точек зрения и, в конечном итоге, построение логики понимания процесса, которую можно создать путем выработки комплекса взаимосвязанных гуманитарных замыкающих абстракций. Об общественной актуализации этой задачи можно судить по тому, с какой настойчивостью в последнее время представители разных отраслей гуманитарного знания стали говорить о неотложности решения задачи выработки формы и содержания «общенациональной идеи». Очевидно, что интегрировать различные области знания воедино без выделения базовых смыслов осевого времени невозможно [Ясперс 1991, 32]. Поэтому любопытно представить даже краткий очерк подобных попыток, предпринятых разными культурами в разные времена с целью достижения смыслового согласования различных задач социальной практики. Оговоримся, что наш исторический экскурс не претендует на широту и всеохватность. Мы лишь постарались, насколько возможно, определить узловые смыслы, важные для настоящего изложения. В этой связи мы элиминировали фрагменты истории Древней Индии, Китая, Египта и тому подобных не по причине признания их несущественности, но только по соображениям сохранения определенной, скорее формальной однородности.

Уже античная интеллектуальная практика пришла к выводу о необходимости выделения вопроса о том, что «есть и почему» такое понятие, как «качество жизни» (заметим попутно, что разные античные авторы, говоря об одном и том же явлении, нередко называли его по-разному). Это обстоятельство кардинально отличало античный характер спекулятивных построений от предшествующего мифологического опыта, заложив тем самым основы научной европейской традиции. Гераклит, Демокрит, Аристотель - особенно в своей «Никомаховой этике» [Аристотель 1984, 65], уже стремились к созиданию научного понимания смыслов жизни и истории, которое было бы открыто для научной критики. И эта интенсиональная характеристика античного научного знания не замедлила проявиться в космологических идеях Демокрита [Лурье
1970, 207], диалектических идеях Гераклита, которые своеобычно связывали мир человека и мир космоса и, наконец, Аристотель в своих «Аналитиках» [Аристотель 1952] достиг высот античного понимания необходимости бережного отношения к здоровью как одной из величайших социальных ценностей. В целом, античность стремилась к тому, чтобы охватить смыслы взаимодействия «человек-природакосмос» на уровнях всеобщего (космические связи) и индивидуального (судьба).

Космологическая идея античности со временем уступает место теоцентристской идее средневековья. Попытки античных авторов облагородить космологическую идею, вложить в нее гуманистическое содержание наталкивались на объективно существующие базовые связи античной экономики, которые, как известно, формально-юридически были рабовладельческими, следовательно, неизбежно базировались на насилии, то есть на внеэкономическом принуждении к труду. Отсюда рождалась социальная оппозиция «господин - раб», преодолеть которую античность в условиях наличного существования не сумела. Получалось так, что о проблемах человека, его жизни и здоровье говорить в общезначимых смыслах, с одной стороны, было культурно притягательно, но с другой, социально-экономической, попросту невозможно: очевидно, что единого социального измерения в условиях оппозиции «раб - господин» не создать.

Вот почему снятие этого противоречия исторически происходит, как говорилось выше, в форме теоцентризма, когда диаметрально меняются декорации истории и «мир справедливости и добра навсегда поселяется на небе». Со времени Августина Блаженного идея о «граде Божием» и «граде земном» [Августин Блаженный 1998] претерпевает значительные видоизменения, сохранив неизменным стремление связывать все сущее, в том числе качество индивидуальной жизни, ее благополучие исключительно с идеей божественного начала как всеопределяющего. Казалось, что «золотой ключик» ко всем проблемам найден, но торжествовать победу пришлось недолго.

По мере роста общей численности и, главное, плотности населения резко обострились многие проблемы социальной жизни, которые и ранее доставляли немало хлопот 
(организация скорой медицинской помощи, госпитальное дело, медицинское образование, аптечное дело и так далее). Кроме того, появились принципиально новые формы социальной активности (торговля, банковские сети, массовые профессиональные армии и так далее), которые на первый план выдвигали вопросы организации массовой санитарии и гигиены, акушерства, эпидемиологии и т. п. Могло показаться, что источник бед и волнений находится где-то вовне и с самими людьми непосредственно не связан. С внешней же угрозой злых сил мира люди привыкли справляться с помощью умилостивительных молитв.

Историческое время заставило успокоившегося в канонах веры человека вздрогнуть, когда ему был предъявлен схоластический парадокс о том, что всемогущий Господь, если он действительно всемогущ, должен создать камень такого веса, который он не сможет поднять. Кончина теоцентристской идеи, которая предполагала решить все земные проблемы (благополучие, здоровье, счастливая жизнь) либо в Боге, либо посредством Бога, произошла именно тогда, когда усилиями Пьера Абеляра и Фомы Аквинского [Гусейнов, Иррлитц 1987, 50] была создана концепция «ангельского доктора», но поставить победную точку история не смогла, поскольку сама идея отнесенного «вовне» решения всех проблем, увы, оказалась несостоятельна по чисто логическим основаниям.

Оказавшись на очередном историческом переломе, культура Возрождения и Нового времени резко меняет смысловые акценты, переселяет субъекта исторических драм с небес на землю, где он и должен искать разрешение противоречий своего социального бытия. Наиболее подходящей и в теоретическом и в практическом плане оказалась доктрина антропоцентризма, которая и заменяет с собой парадигму теоцентризма.

Суть этих изменений наиболее полно выразил в своих работах Н. Кузанский, определив человека как исходную точку вселенной. Он практически все замкнул на человека. В этой ситуации Кузанскому не оставалось иного пути, кроме дороги абстрактного гуманизма. Однако абстракция как таковая означает отбрасывание лишних признаков. Стремясь подчеркнуть вселенские черты челове- ческого «Я», Кузанский оставлял в стороне «мелкие подробности» его бытия, в число которых входили и образование, и здравоохранение, и воспитание, то есть то, что и лежит в основе процесса обработки людей людьми, наполняет историческое время конкретикой, делает его узнаваемым [Кузанский 1937].

Последующие шаги общества Нового времени как раз и были связаны с внесением в способ понимания человеческого блага в том числе и здоровья, уже явно различимых оттенков инструментализма, подчеркивающих роль и значимость конкретно-социальных параметров человеческой личности, закрепленных в нормах общественного права.

Сравнивая Новое время с античностью, мы замечаем, что произошел исторический сдвиг эпох, изменились нравы, язык, законы и многое другое, однако историческая сердцевина сумела сохранить себя в своей сути: насилие как таковое продолжало оставаться доминантой истории. Однако от ничем не ограниченного насилия Древнего мира цивилизация Европы XVII в. приблизилась к реализации ограниченного, хоть и частично, права насилия. Поэтому логика общественного договора Томаса Гоббса знаменовала собой наступление новой исторической эпохи. Эта доктрина уже напрямую связывает природное, естественное состояние индивидуальных проявлений человека с юридически закрепленными возможностями (подчеркнем, только возможностями) обретения им гражданских качеств, которые он получает в процессе социализации.

Простые и ясные истины, совпадающие и по форме и по содержанию с нормами естественной, простой этики и нормами естественного гражданского права совсем не органично вписывались в мир реальный.

Следует отметить, что Новому времени, помимо правовой манифестации ценностей и последующего включения в перечень естественных прав вопросов жизнесохранения, нужно было еще и научиться таким областям социальной практики, как обмен видов деятельности, организация распределения и потребления, социальное функционирование семей и так далее. И здесь оказалось, что практики духовного и материального производства расходятся. Нормы абстрактного гуманизма Кузанского плохо согласовывались с суровы- 
ми законами нарождающегося рынка: оказалось, что здоровье - такой божественный дар, за который надо платить. Если это так, то тогда возникает множество острых вопросов: кто, сколько, когда, кому, гарантии и так далее.

Обозначившееся социально-экономическое неравенство приняло облик революционных идей. Из дальнейшего изложения станет ясно, что возникает любопытный парадокс: люди все глубже запутываются в связях и отношениях, которые создают сами.

Очарование революционной фразой оказалось таким захватывающим, что, забыв скептицизм Монтеня, логический рационализм Декарта и субстанциональную проницательность Спинозы, Европа пала жертвой революционного романтизма и нетерпеливости, когда вместе с правом на жизнь, свободу и труд (в будущем эта ценностная триада трансформируется в девиз Великой французской революции «Свобода, Равенство, Братство»), в числе естественных прав стали мыслиться и права охранять свое здоровье, заботиться о здоровье старших и младших поколений и так далее. Таким образом, люди достигли уровня развития, когда важность задачи надо было согласовывать с ресурсным обеспечением и благовременностью [Конституции... 1957, 232].

Поставленные Томасом Гоббсом задачи [Гоббс 1989, 327] в целом совпадали с вызовами исторического времени. Однако их надо было не только обозначить, но и как-то реализовать, сообразуясь с созданной жизнеой конкретикой, то есть различать их в своеобразном переплетении вкусов, запахов, звуков.

Развивая эту идею, Иммануил Кант дает ее философское завершение (актуальное, кстати, и сегодня, но подробнее об этом скажем ниже) в виде утверждения единства добродетели и благополучия [Кант web].

При всем многообразии гуманитарных идей Нового времени обращает на себя внимание неприкрытое стремление ставить логическое ударение на «естественном» праве людей на жизнь и здоровье, подчеркивая его историческую автономность. В результате вопросы о зонах ответственности, модификации общественного устройства жизни людей, определении глубины и границ государственного правового регулирования и социальной политике отодвигались куда-то вдаль. Попут- но заметим, что обретенное в истории социальное качество отнюдь не утрачено, а продолжает сохраняться, пусть и в несколько измененном виде, в современном воплощении в жизнь либеральной идеи. Достаточно оглянуться на социальные волнения ХХІ в. в США, Франции, ФРГ, чтобы понять какую подлинную цену приходится платить за постижение очередности философских и социологических истин, столь далеких от житейских установок текущего времени.

Вернемся к Новому времени, чтобы сделать одно существенное, на наш взгляд, дополнение. Мы уже отмечали, что Европа, нащупав социальную продуктивность естественно-правовой идеи, пусть и не очень уверенно, но все-таки двинулась по этому пути. Однако правовая эйфория длилась относительно недолго по следующим основаниям.

Первое и самое главное затруднение заключалось в том, что естественно-правовой идеал изначально мыслился как некое универсальное средство от всех бед [Гоббс 1991, 98], которое на глазах теряло свои волшебные свойства, сталкиваясь с канонами национальных правовых систем. Таким образом, правовая форма вступила в острое противоречие с правовым содержанием. До конца разобрать эти завалы не удается до настоящего времени, о чем можно судить по политическому развитию современной России. Став правовым государством, она, тем не менее сталкивается в медицинско-правовой области с серьезными проблемами и противоречиями. Справедливости ради, заметим, что она далеко не одинока в этом отношении.

Второе открытие состояло в том, что проблема здравоохранения оказалась бинарной, то есть помимо прямой связи «государство - врач - пациент», существовала и обратная, ведущая от пациента к врачу. В тексте Библии, видимо, не случайно присутствует строгий императив: «Врачу исцелися сам...» (Лк. 4:23), и тем не менее Европа все же решительно вступила на этот оказавшийся тернистым путь развития.

Достигнув высот эпохи Просвещения, Западная Европа всерьез поверила, что в конце XVIII в. уже не за горами вступление в вожделенное царство Разума, где Мировой Логос определяет все, начиная от установления 
законов небесной механики и кончая точными указаниями в области оптимальной организации лечебного дела вплоть до правил посещения лазаретов (античному Гераклиту в сей момент, видимо, стало светло на небесах). Захваченным революционным вихрем европейцам дела земные казались не сложнее бинома Ньютона.

Действительно, в то время задача не казалась такой головокружительно сложной. В качестве возможных препятствий виделась известная медико-биологическая недосказанность (гносеологический оптимизм эпохи с этими опасениями легко справлялся), некоторое ослабление исторической воли к действию, с которым Владимир Маяковский чуть более века спустя предлагал бороться прямым понуканием: «Клячу истории загоним! - Левой, левой, левой!» [Маяковский 2019, 193] Исторические перспективы радовали, поскольку были явно ощутимы революционные напор и решительность. Может быть, потому и возникает идея Артура Шопенгауэра о воле как главном двигателе истории [Шопенгауэр 2016, 3]. Российская интеллектуальная молодежь XIX в. буквально зачитывалась Шопенгауэром.

Мы недаром так пристально оглядываемся в дела давно минувших лет, ибо часть подобных ошибок в отечественной социальной практике мы уже совершили, а некоторые еще впереди и, может быть, мы будем о них только помнить, но не переживать.

Однако Европе XVIII в. еще предстояла встреча с «историческим» дьяволом, который, как известно, кроется в мелочах. И он не замедлил явиться тогда, когда его появления совсем не ожидали.

Мы уже частично коснулись вопроса о роли перемен в динамике восприятия медико-социальной сферы. Не обошли они стороной и начало XIX в., совпавшего с целым рядом глобальных процессов. Начавшаяся индустриализация, подвижки в организации и ведении сельского хозяйства, массовые социальные миграции как по вертикали, так и по горизонтали, формирование нового социального портрета семьи, тотальная урбанизация и многое другое были порождением этого времени. Меновый рынок, задававший до этого значения основных социальных показателей (образ и качество жизни), стал уступать мес- то рынку капиталов, что означало вступление исторического человека в эру отчуждения. Не вдаваясь в подробности, отметим, что "Ното sapiens" (продукт эпохи Просвещения), встретившись с "Нomo faber" (индустриальный продукт), незаметно для себя утратил свою самость. Произошло это прежде всего потому, что отношения стали всезначимыми и оттеснили человека и присущие ему по своей природе проблемы (здоровье, благополучие и т. д.) на историческую периферию. Таким образом, человек отчуждается от всего, всех и самого себя, все заслоняет собой капитал, становясь молохом современности. Идея «выгода, ничего, кроме выгоды» превратились в альфу и омегу истории, вобрав в себя ее смыслы и значения.

В соответствии с указанным сдвигом в мировосприятии произошли и кардинальные изменения в системе социальных ориентаций человека, которые привели к серьезным деформациям представлений о качестве жизни. Глубинная суть произошедших изменений отразилась в системе взглядов, получивших название философии утилитаризма. Джон Милль, ее основоположник, решительно отходит от принципов культуры, характерных для античности и эпохи Возрождения. Он прямо и бесповоротно говорит о том, что только принцип пользы может служить в качестве истинного универсального мерила всех без исключения желаний и устремлений [Прокофьев 2008a, $118 ;$ 2008б, 137]. Возникшая чуть позже моральная арифметика Иеремии Бентама окончательно определила метод количественной калькуляции счастья как способ подсчета количества людей, которые считали, что необходимый по их мнению и согласно общественным стандартам счастья (вспоминается смысловое клише «американская мечта») уровень жизни уже достигнут [Философский энциклопедический словарь 1983, 49]. Любопытно отметить то обстоятельство, что примерно в это же время (1-я треть XIX в.) возникает и наука под названием социология - выдающееся достижение Огюста Конта, который в своем детище, в первую очередь, видел инструмент социального измерения [Конт 2011, 54].

Огюст Конт одним из первых оценил методологический и прогностический потенциал социологической науки, которая благода- 
ря своим инструментальным возможностям смогла измерять социальные факторы, явления, процессы. Мир социологических выкладок своей цифровой конкретикой убеждал человеческие массы быстро и доходчиво. Так начиналось очарование цифрой, которое длится и поныне. Оно дало удивительные результаты, порой ошарашивающие. Подробнее на этом остановимся ниже.

Индустриальная Европа и Америка XIX$\mathrm{XX}$ вв., достигнув своего имперского величия, видимо, полагали, что сумеют освоить социально-гуманитарную тематику без принципиальных затруднений, но в начале XX в. в России произошла цепочка социально-экономических революций, которая решительно изменила ход мировой истории. Оставляя в стороне разбор социально-экономических проблем (это выходит за рамки поставленной в статье задачи) революционной эпохи, отфиксируем одно из важнейших ее достижений в гуманитарной сфере. Речь пойдет о системе защиты населения и охранездоровья, разработанной Н.А. Семашко в послереволюционные годы [Решетников и др. 2014]. Система (модель здравоохранения в СССР) активно обсуждается в современной научной литературе. Несмотря на различие точек зрения экспертов, они сходятся во мнении, что эта система и сегодня впечатляет своей эффективностью. Скажем прямо: ее сохранившиеся отдельные механизмы продолжают эффективно действовать и сегодня. Достаточно сказать, что успехи Российской Федерации в борьбе с COVID-19 в немалой степени достигнуты благодаря элементам указанной системы. Она, конечно, не может рассматриваться как образцовая модель общественной защиты здоровья, но ее базовые ценности и стандарты заслуживают самого серьезного внимания. Это тем более важно, потому что западный мир в это же самое время достигал своих результатов. Однозначно о них судить трудно, там были и свои победы и свои поражения. Нащупав социальную продуктивность естественно-правовой идеи, западные страны, а теперь и Россия, заявившая в своей Конституции о том, что является правовым государством, пусть и не очень уверенно, но все-таки свою социальную политику строит по рецептам Гоббса и Монтескье, предпочитая не вспоминать Карла Маркса. До настоящего времени казалось, что рецепт процветания найден и главное теперь - не сойти с этого пути. Однако перемены не заставили себя долго ждать. Прежние уклады жизни: и индустриальный капитализм, и социалистическая экономика, и постиндустриальное общество, и турбокапитализм - вынужденно уступили историческую дорогу информационным технологиям, которые создали прежде всего новый темп реальности, в котором цифровой и физический миры слились воедино, сделав границу, их разделяющую, почти неразличимой.

Изменения коснулись и медицинской сферы, традиционная медицина серьезно потеснена нетрадиционной, лечить стали не болезнь, а симптомы, охрана здоровья из медицинской сферы переместилась в социально-правовую.

Наука, издревле соединявшая себя с социальной практикой посредством философской объективации, ныне осознается и закрепляется в общественном сознании напрямую, проходя при этом фильтры социально-психологической оценки. О качестве жизни, например, стали говорить как о чем-то таком, что фиксируется на уровне чувственного восприятия.

К этому следует добавить, что такая исконная ценность буржуазного толка как деньги, эволюционировав, превратилась в универсальное мерило всего: на полном серьезе в ходе судебных слушаний на Западе устанавливается средняя (интересно для кого вопрос) стоимость человеческой жизни.

Поддавшись обаянию идеи универсализма, мы стремимся к обобщению повсюду, начиная от рационализации наполненности финансовых потоков (одно только таргетирование бюджетных средств чего стоит) и кончая оптимизацией кадрового менеджмента (еще недавно это называли проще - «сокращение штатов»).

В современном мире здоровье, будучи оцифрованным, определяется по величине денежного эквивалента защищающего его полиса. В этой системе социального измерения уже начинает волновать не само здоровье, а размер суммы полиса, источники финансирования, банковские гарантии. Глядя на серьезные социальные волнения, например, в США, в последнее время, нельзя не заметить, что именно противоречия в системе полисной организации национального здравоох- 
ранения поставили страну на грань гражданской катастрофы.

Очень не хотелось бы сводить существующие проблемы только к количественной стороне дела: подсчет страховых сумм полисов, их коррекция и так далее. Или углубляться в бесконечные перечисления и уточнения соответствующих правовых актов. Безусловно, эти вопросы важны, иногда болезненны, но куда более важным представляется вопрос о том, что такое милосердие? Это профессиональная компетенция социального работника со своим укладом, тарифной сеткой, должностной инструкцией? Или коснемся совсем уж запутанного вопроса о волонтерстве, которое должно быть олицетворением жертвенности, филантропии, с одной стороны, а с другой, становится придатком службы спасения «911».

Казалось бы, и первые и вторые озабочены вопросами опеки, помощи пострадавшим людям. Но попробуйте хотя бы скоординировать одновременно работу тех и других. Скорее всего не получится.

Современная модель либерального толка, охватывая собой новые регионы и социальные солидарности живущих в них людей (социальные конвиксии и консорции, социальные слои, профессиональные группы, страны), стала все больше напоминать своей губительной силой чуму, но уже XXI века.

По своей сути современная социальная практика создает своего рода социальные оксюмороны типа «горячий снег», «добрый волк» и так далее. Почему это происходит? Отважимся дать свою версию ответа.

Мы не случайно начали наше изложение с сетования на времена перемен и связанные с ними перестройки смыслов, которые глубоко меняли исторические формы культуры в общем и связанные с ними формы организации гуманитарного знания в частности. Мы все еще пытаемся в логике событий былого найти подсказку действий в будущем. Отсюда и наш экскурс в историю гуманитарных взглядов, как-то само собой в памяти всплывает грозное предостережение Гегеля, что история ничему не учит человека.

Тогда приходится соглашаться с тем, что в условиях наступившей цифровизации, демографической «гармошки», мультикультурности и всепроникающей толерантности мы в боль- шей степени, нежели наши предки, обречены на историческое одиночество. Стоя на семи ветрах системы вызов-ответ, мы должны твердо помнить, что нам не избежать общей исторической участи: в эпоху перемен надо создавать новые научные теории, новые подходы к решению социальных проблем.

В процесс обновления социальных и гуманитарных наук стягивается вся цивилизация без остатка. Причина этого заключается в испуге «цивилизованного» человека перед творением рук своих. Снося социальные конструкции прошлого, сторонники «новой волны», охваченные безудержной страстью стремления к социальной новизне, безжалостно разрушают ценностную базу традиционной культуры. Рушится все: начиная от ценностей, привитых литературой и искусством, и заканчивая семейными ценностями (нет уже в ряде социальных систем статусов «муж» и «жена», а есть «однополый и двуполый брак»), гендерными характеристиками (помимо статусов «мужское» и «женское» появился статус «трансвестит»). Поэтому в социальной практике возникают неразрешимые вопросы. Например, включать трансвестита в систему мужского или женского здравоохранения или одновременно в обе. За всем этим стоит не только серьезное медико-биологическое различие, это одновременно и целые пласты истории со своим языком, устоями, нормами. Попытка при этом спрятаться за словами «политкорректность» и «толерантность» поневоле заставляет думать о преднамеренном искажении культурных ценностей целых народов.

В начале XXI в. западная цивилизация пришла к выводу, что метод прямой экстраполяции истории перестает работать [Хобсбаум 2004, 13]. До недавней поры «прошлое» незаметно перетекало в «настоящее» и затем превращалась в «будущее». И это обстоятельство воспринималось как непреложный закон естественной и социальной истории.

Первый тревожный звонок раздался в 1945 г., когда гибельное атомное пламя впервые вспыхнуло над Хиросимой. Хибакуся стали символами не только военной жестокости, но и удручающей человеческой глупости. Чем дальше и глубже люди проникали во тьму времен, тем очевиднее как для цивилизации в целом, так и для ее национальных сегментов становилась задача овладения новым уровнем 
не только естественного, но и гуманитарного знания, поскольку все острее и беспощаднее становились проблемы социальной биологии человечества, о которых мы уже говорили.

Осознавая для себя эту задачу, западные страны посчитали, что могут решить ее самостоятельно. Россия, таким образом, как это уже не раз бывало в истории, должна была снова искать внутренние силы для нахождения достойного ответа. А они действительно были прежде всего в динамике научной мысли, в развитии технологий.

Однако не будем забывать, что историческая изменчивость решительно меняет и форму и содержание таким образом, что уровень нагрузок на людей вырос до таких пределов, преодолеть которые можно лишь создав культуру нового типа. Речь не идет о возрождении ницшеанских социальных проектов или каких-то иных подобных ему, но мы говорим о формировании философско- социологической интегральной концепции человека, в которой философское онтологическое понимание органически сольется с конкретно социологическим объяснением сложных механизмов социального и экологического развития Homo sapiens.

Таким образом, смысловая нагрузка понятий, связанных со здоровьем и медицинской наукой напрямую зависит от социокультурной матрицы и тем самым определяет эволюцию понимания здоровья индивидуумом как ценности и экономической категории. Здоровье уже не является определением физического состояния тела, оно включает в себя психическое, душевное и социальное благополучие. Здоровье бесценно как субъективная категория, но имеет и вполне вычисляемую экономическую составляющую с точки зрения социальной защиты. Эти факты, с нашей точки зрения, доказывают необходимость появления новой социально адаптированной модели медицинского обслуживания населения, опирающейся на анализ результатов многомерного социологического изучения потребностей людей в сфере здравоохранения.

\section{СПИСОК ЛИТЕРАТУРЫ}

Августин Блаженный 1998 - Августин Блаженный. Творения. В 4 т. Т. 3. О Граде Божием. Кн. IХІІІ. Киев: УЦИММ-Пресс, 1998.
Аристотель 1952 - Аристотель. Аналитики первая и вторая. Ленинград: Гос. изд-во полит. лит., 1952.

Аристотель 1984 - Аристотель. Сочинения. В 4 т. Т. 4. М.: Мысль, 1984.

Гоббс 1989 - Гоббс Томас. Сочинения. В 2 т. Т. 1. М.: Мысль, 1989.

Гоббс 1991- Гоббс Томас. Сочинения. В 2 т. Т. 2. М.: Мысль, 1991.

Горшков, Крумм, Тихонова 2013 - Горшков М.К., Крумм Р., Тихонова Н.Е. Готово ли российское общество к модернизации? М.: Весь Мир, 2010.

Гусейнов, Иррлитц 1987 - Гусейнов А.А., Иррлити Г. Краткая история этики. М.: Мысль, 1987.

Кант web - Кант И. Метафизика нравов. Введение в учение о добродетели [Гражданское общество в России] // https://www.civisbook.ru/files/ File/Kant_Metaphisika_4.pdf.

Конституции... 1957 - Конституции и законодательные акты буржуазных государств XVIIХІХ вв. / под ред. П.Н. Галанзы. М.: Госюриздат, 1957.

Конт 2011 - Конт О. Общий обзор позитивизма. М.: ЛИБРОКОМ, 2011.

Кузанский 1937 - Кузанский Н. Избранные философские сочинения. М.: Соцэкгиз, 1937.

Лурье 1970 - Лурье С.Я. Демокрит. Тексты. Перевод. Исследования. Ленинград: Наука. Ленингр. отд-ние, 1970.

Маяковский 2019 - Маяковский В.В. Стихи и поэмы. Подробный иллюстрированный комментарий к избранным произведениям. М.: Проспект, 2019.

Прокофьев 2008а - Прокофьев А.В. Идея справедливости в «Утилитаризме» Дж.С. Милля // Философия и культура. 2008. № 10. С. 118-133.

Прокофьев 20086 - Прокофьев А.В. Идея справедливости в «Утилитаризме» Дж.С. Милля // Философия и культура. 2008. № 11. С. 137-144.

Решетников и др. 2014 - Решетников В.A., Heсвижский Ю.В., Касимовская Н.А. Н.А. Семашко - теоретик и организатор здравоохранения // История медицины. 2014. № 3. С. 24-29.

Философский энциклопедический словарь 1983 Философский энциклопедический словарь. М.: Сов. энцикл., 1983.

Хобсбаум 2004 - Хобсбаум Э. Эпоха крайностей: Короткий двадцатый век (1914-1991). М.: Независимая Газета, 2004.

Шопенгауэр 2016 - Шопенгауэр А. Феномен воли. С комментариями и объяснениями. М.: АСТ, 2016.

Ясперс 1991 - Ясперс К. Смысл и назначение истории. М.: Республика, 1991. 
A.А. Бобошко. Эволюция смыслового восприятия явлений и процессов в медико-социальной сфере

\section{REFERENCES}

Augustin the Blessed, 1998. Creations. In 4 vols. Vol. 3. About the City of God. Books I-XIII. Kiev, UCIMM-PRESS.

Aristotle, 1952. Analysts the First and the Second. Leningrad, Gos. izd-vo polit. lit.

Aristotle, 1984. Essays. In 4 vols. Vol. 4. Moscow, Mysl' Publ.

Gobbes T., 1989. Essays. In 2 vols. Vol. 1. Moscow, Mysl' Publ.

Gobbes T., 1991. Essays. In 2 vols. Vol. 2. Moscow, Mysl' Publ.

Gorshkov M.K., Krumm R., Tikhonova H.E. 2013. Is the Society Ready for Modernization? Moscow, Ves'Mir Publ.

Huseynov A.A., Irrlicht G., 1987. A Brief History of Ethics. Moscow, Mysl' Publ.

Kant I. Metaphysics of Moral. Introduction to the Doctrine of Virtue. Grazhdanskoe obshestvo v Rossii. URL: https://www.civisbook.ru/files/File/ Kant Metaphisika 4.pdf.

Galanza P. $\overline{\text { N}}$. (ed.), 1957. Constitution and Legislative Acts of the Bourgeois States XVII-XIX Center. Moscow, Gosurizdat Publ.

Kont O., 2011. General Overview of Positivism. Moscow, Librokom Publ.
Kusanskiy N., 1937. Selected Philosophical Works. Moscow, Sotselkgiz Publ.

Lurie S.Y., 1970. Democritus. Texts. Translation. Researches. Leningrad, Nauka. Leningrad. otd-nie.

Mayakovskiy V.V., 2019. Verses and Poems. Detail Illustrated Commentary on Selected Works. Moscow, Prospect Publ.

Prokofiev A.V., 2008a. The Idea of Justice in «Utilitarianism» G.S. Mill. Philosophy and Culture, no. 10, pp. 118-133.

Prokofiev A.V., 2008b. The Idea of Justice in «Utilitarianism» G.S. Mill. Philosophy and Culture, no. 11, pp. 137-144.

Reshetnikov V. A., Nesvizhskiy V. A., Kasimovskaya N.A., 2014. N.A. Semashko - Theorist and Organiser of Public Health. Istoria Medicine, no. 3, pp. 24-29.

Philosophical Encyclopedic Dictionary, 1983. Moscow, Sovetskaya enciklopediya Publ.

Hobsbaum A., 2004. The Age of Extremes: The Short 20 $0^{\text {th }}$ Century (1914-1991). Moscow, Nezavisimaya Gazetha Publ.

Schopenhauer A., 2016. The Phenomenon of Will. With Comments and Explanations. Moscow, AST Publ.

Jaspers K., 1991. The Meaning and Purpose of the History. Moscow, Respublica Publ.

\section{Information About the Author}

Artem A. Boboshko, Candidate for a Degree, Department of Sociology and Social Technologies, Volgograd State University, Prosp. Universitetsky, 100, 400042 Volgograd, Russian Federation; Member of the Public Chamber of the city of Sevastopol, Lenina St, 4, 299011 Sevastopol, Russian Federation, artembobo@bk.ru,https://orcid.org/0000-0001-6990-7282

\section{Информация об авторе}

Артем Андреевич Бобошко, соискатель кафедры социологии и социальных технологий, Волгоградский государственный университет, просп. Университетский, 100, 400062 г. Волгоград, Российская Федерация; член Общественной палаты г. Севастополя, ул. Ленина, 4, 299011 г. Севастополь, Российская Федерация, artembobo@bk.ru, https://orcid.org/0000-0001-6990-7282 